\title{
Fire simulation and smoke spread analysis of subway stations at different fire locations
}

\author{
Yuan Linlin ${ }^{1 *}$, Yang $\mathrm{Mo}^{1}$ \\ ${ }^{1}$ University of Shanghai for Science and Technology, Shanghai 200093, China
}

\begin{abstract}
In order to explore the law of smoke spread in the fire environment of an island-style subway station, this article takes an island-style subway as the research object. Based on the fire dynamics, pyrosim is used to establish a subway fire model to observe the smoke concentration and temperature changes under different fire locations. The study found that when the fire source is at the end of the platform layer, the flue gas concentration of the farthest evacuation channel and safety exit reaches $80 \%$ at $85 \mathrm{~s}$ and $130 \mathrm{~s}$, respectively, and the flue gas temperature at the nearest exit and the farthest exit are at $32^{\circ} \mathrm{C}$ and $28^{\circ} \mathrm{C}$ respectively. When the fire source is in the middle of the platform layer, the smoke concentration of the evacuation channel and the safety exit reaches $80 \%$ at 70 s and 105 s respectively, and the temperature of the smoke at the exit exceeds $40^{\circ} \mathrm{C}$.
\end{abstract}

\section{Introduction}

With the development of the world's urbanization process, the population density in highly developed cities has gradually increased, and the construction requirements of urban public transportation have also increased. Among the many means of transportation, the subway has the

Table 1. Subway accident sorting.

\begin{tabular}{|c|c|}
\hline Time & Accident \\
\hline $\begin{array}{l}\text { February } \\
2003\end{array}$ & An arson occurred at a subway station in Daegu, South Korea, causing 198 deaths and 146 injuries. \\
\hline $\begin{array}{l}\text { December } \\
2003\end{array}$ & $\begin{array}{l}\text { A fire broke out in a shopping mall adjacent to a subway station in Shanghai, China, and smoke spread to the } \\
\text { subway station. }\end{array}$ \\
\hline June 2013 & $\begin{array}{c}\text { A power line failure at a subway station in Moscow, Russia caused } 52 \text { people to be injured and about 4,500 } \\
\text { people were evacuated urgently. }\end{array}$ \\
\hline January 2015 & A fire broke out in a subway in Washington, U.S., causing 1 death and 2 injuries \\
\hline October 2016 & An unknown substance burned in the vent of a subway station in Tokyo, Japan, and the subway was suspended. \\
\hline June 2018 & $\begin{array}{c}\text { A subway station in London, the United Kingdom exploded due to overheating of electronic equipment, and a } \\
\text { large amount of smoke spread in the subway station. }\end{array}$ \\
\hline October 2019 & Arson occurred at multiple subway stations in Hong Kong, China, and the subway was paralyzed. \\
\hline
\end{tabular}

Therefore, the subway fire is of great research value and practical significance. Park et al. established a numerical model to study the diffusion rate of smoke at different locations in a subway fire, and analyzed and compared the distribution of smoke, temperature, and advantages of small footprint, large passenger capacity, and stable operation. It is the best choice for most people to travel. However, the subway also has the characteristics of large flow of people, prone to congestion, and long evacuation time. Once a fire occurs, it is very easy to cause serious casualties. Table 1 summarizes some subway fire incidents in countries around the world ${ }^{[1]}$. 
used in the fire scenes of various buildings ${ }^{[4,5,6]}$.

Based on fire dynamics, this paper takes a subway station as the research object and establishes a simulation model through Pyrosim, and obtains the smoke concentration changes and temperature changes of the stairs and exits near different fire sources in subway fires.

\section{PRELIMINARIES}

Fire Dynamic Simulation (FDS) is a computational fluid dynamics (CFD) model of fire-driven fluid flow, and it is also the most widely used fire calculation simulator ${ }^{[7]}$. Fire dynamics believes that fire is a physical and chemical process, and its combustion process obeys the following conservation laws:

(1) Continuity equation:

$$
\begin{gathered}
\frac{\partial \rho}{\partial t}+\nabla \cdot \rho \vec{\mu}=0 \\
\nabla \cdot \vec{\mu}=\frac{\partial u}{\partial x}+\frac{\partial v}{\partial y}+\frac{\partial w}{\partial z}
\end{gathered}
$$

Where, $\rho$ is the density; $t$ is the time; $\vec{\mu}$ is the speed;and, $u, v$ and $w$ are the components of the speed in the three coordinate axis directions.

(2) Conservation of momentum:

$$
\rho\left(\frac{\partial u}{\partial t}+(u \cdot \nabla) u\right)+\nabla p=\rho g+f+\nabla \cdot \tau
$$

Where, $g$ is the acceleration due to gravity; $f$ is the externally applied force vector; $\tau$ is the viscous force tensor; $p$ is the pressure.

(3) Energy equation:

$$
\begin{aligned}
& \frac{\partial}{\partial t}(\rho h)+\nabla \cdot(\rho h u)=\frac{\partial p}{\partial t}+u \cdot \nabla p-\nabla \cdot q_{r}+\nabla \cdot(k \nabla T) \\
& +\sum_{i} \nabla \cdot\left(h_{i} \rho D_{i} \nabla Y_{i}\right)
\end{aligned}
$$

Where, $h$ is the enthalpy $(\mathrm{J} / \mathrm{kg}) ; q_{r}$ is the thermal radiation energy; $T$ is the temperature; $k$ is the thermal conductivity.

\section{Simulation modeling}

This paper takes an island-style subway station as the research object, and establishes a physical model in the software Pyrosim according to its basic situation and spatial structure. The top view is shown in 1 . The station hall floor B0 and the station floor B1 are both $115 \mathrm{~m}$ long, $24 \mathrm{~m}$ wide, $4.5 \mathrm{~m}$ high, and the total area is about 5520.0 $\mathrm{m}^{2}$. There are two stair evacuation passages between the station floor and the hall floor, and there are two on each side of the wall of the station hall floor. There are 48 screen doors evenly distributed on both sides of the platform layer.

Pyrosim can observe the smoke concentration, smoke height and temperature changes in the subway station when a fire occurs, and add 24 smoke detectors and 24 temperature detectors, 3 carbon monoxide concentration measuring devices, and 4 slice devices. Display 2D outline. In order to observe the influence of fire development at different fire source locations, and to study its smoke content and temperature changes, this paper sets up 4 fire scenarios:

In the Case1, is the fire source is at position 1, on the left side of the platform

Case2: The fire source is at position 2, located on the platform level.

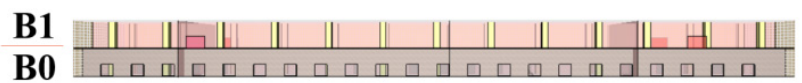

Figure 1. Main view of subway station

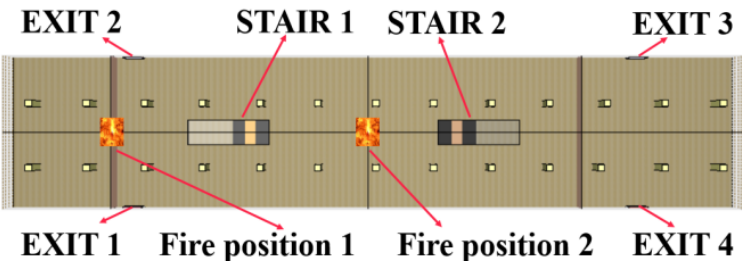

Figure 2. Top view of subway station

\section{Results and analysis}

According to the above model, the fire simulation is performed in Pyrosim, and the result at 600s is shown in Figure 3. Although most of the passengers carried are combustibles, the construction materials of subway stations are basically fireproof materials, so this article only simulates the combustion and smoke near the fire source. It can be found that the higher smoke concentration in Case 1 is at the end of the subway near the fire source, while the smoke concentration and flame temperature in Case 2 are basically symmetrical.

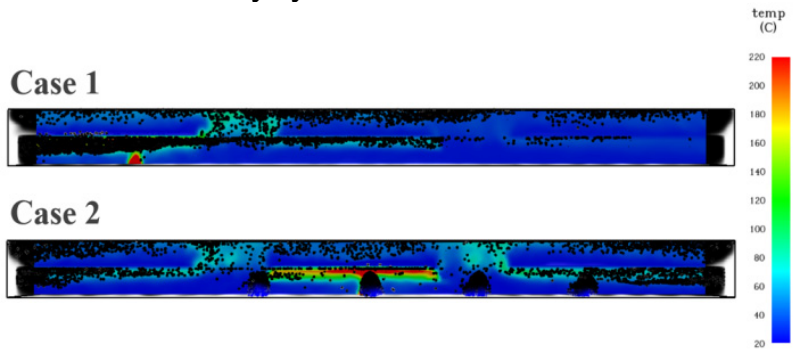

Figure 3. Temperature distribution of smoke and fire source in subway station at $600 \mathrm{~s}$

In Case 1, exit 1 and exit 2 are the closest to the fire source, and the flue gas concentration changes near stairs 1, stairs 2 and exit 4 are shown in Figure 4. It can be seen that the smoke concentration of staircase 1 rapidly exceeded $80 \%$ in the 40 s after the fire, while staircase 2 exceeded $80 \%$ at $85 \mathrm{~s}$, and the exit 4 , which is the farthest from the fire source, gradually exceeded $80 \%$ after 130 s. In Case 2, the distances from the two stairs to the fire source are equal, and the distances from the 4 exits to the fire source are also equal. The flue gas concentration changes near staircase 1 , staircase 2 and exit 4 are shown in Fig. 5. It can be seen that at about 70 s, the smoke concentration near staircase 1 exceeds $80 \%$. After $105 \mathrm{~s}$, the flue gas concentration near the outlet 4 gradually rises to about $75 \%$. 


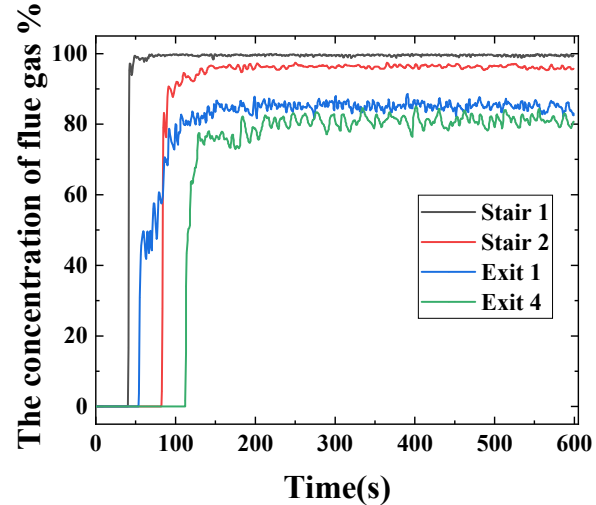

Figure 4. Smoke height at Case 1

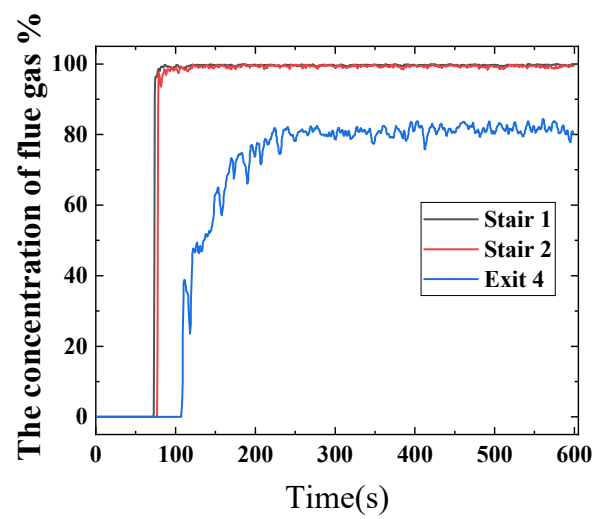

Figure 5. Smoke height at Case 2

The temperature changes near the four exits are shown in Figures 6 to 9. It can be seen that because there are fewer combustibles in the subway station, the fire cannot spread to the hall floor, but the flue gas temperature gradually rises. When the fire source is located at the end of the platform floor, the temperature of the flue gas near the nearest exit is about $30^{\circ} \mathrm{C}$. The flue gas temperature at outlet 3 and outlet 4 gradually increased after 110 s, and finally stabilized at $25^{\circ} \mathrm{C}$. When the fire source is in the middle of the two stairs, the temperature of the 4 outlets all rise gradually after $40 \mathrm{~s}$, and fluctuates around $40^{\circ} \mathrm{C}$.

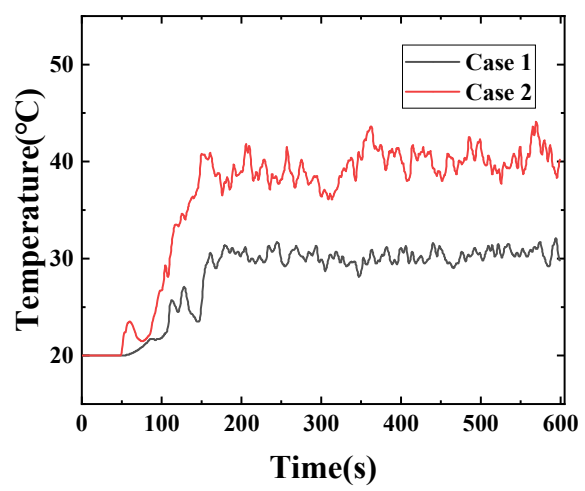

Figure 6. Temperature near exit 1

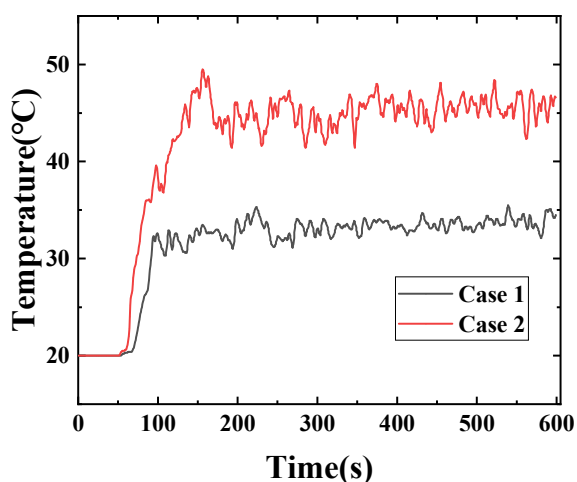

Figure 7. Temperature near exit 2

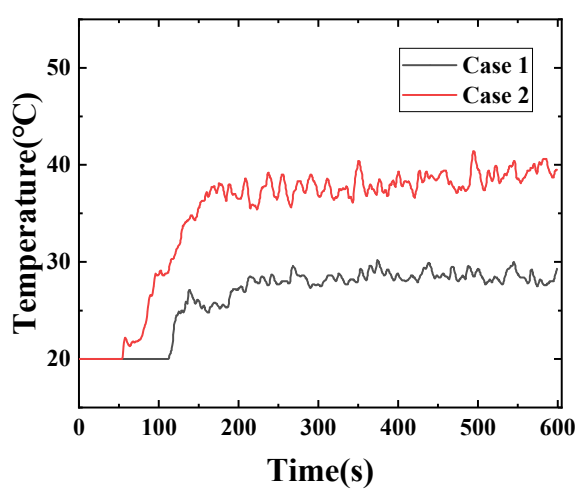

Figure 8. Temperature near exit 3

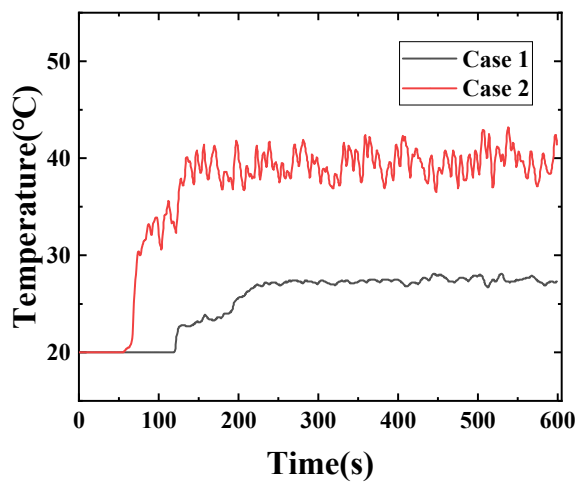

Figure 9. Temperature near exit 4

\section{Conclusion}

Today, when the subway construction tells the development, the subway fire safety issue has new challenges. In order to study the fire safety of subway buildings, this paper uses Pyrosim software to establish a fire simulation model for subway stations. From the modeling results, it is observed that when the subway station is composed of fireproof materials, and with a single fire source which is at the end of the subway platform, the smoke concentration at the nearest stairs, the furthest stairs, the nearest exit and the furthest exit reaches $80 \%$ after $40 \mathrm{~s}, 85 \mathrm{~s}, 95 \mathrm{~s}$ and $130 \mathrm{~s}$, and the smoke temperature at the exits is below than $32^{\circ} \mathrm{C}$. When the fire source is in the middle of the platform floor, the smoke concentration near the stairs and the exit reaches $80 \%$ at 
$70 \mathrm{~s}$ and $105 \mathrm{~s}$, respectively, and the exit temperature exceeds $39^{\circ} \mathrm{C}$. The farther the fire source is from the exit and the evacuation channel, the longer it will take for the smoke concentration and temperature to reach a threat to human health, and the more time left for people to evacuate.

\section{Funding}

This paper was support by the National Natural Science Foundation of China (51736007).

\section{References}

1. Yu Heng. Research on the fire safety evacuation of subway station based on fire dynamics and crowd evacuation simulation [D]. South China University of Technology, 2020.

2. Park, W.H., Kim, D.H., Chang, H.C. Numerical Predictions of Smoke Movement in a Subway Station under Ventilation [J]. Tunneling and Underground Space Technology, 21(3):304-304.

3. Pan, L.W., Lo, S.M., Liao, G.X., Cong, B.H. Experimental Study of Smoke Control in Subway Station for Tunnel Area Fire by Water Mist System [J]. Procedia Engineering, 2011, 11: 335-342.

4. Liang, T., Liu, J., Tao, P. The implementation of the numerical simulation by utilization of pyrosim on the rectification of the hazard of fires. In Proceedings of the 11th International Conference on Computer Modeling and Simulation, pp. 2019:31-35.

5. Manabu Tsukahara, Yusuke Koshiba, Hideo Ohtani. Effectiveness of downward evacuation in a largescale subway fire using Fire Dynamics Simulator [J]. Tunneling and Underground Space Technology incorporating Trenchless Technology Research, 2011, 26(4): 573-581.

6. Roh. J. S, Ryou. H. S, Park. W. H.et al. CFD Simulation and Assessment of Life Safety in a Subway Train Fire [J]. Tunneling and Underground Space Technology, 2009, 24(4): 447-453.

7. McGrattan, K., Klein, B., Hostikka, S., \& Floyd, J. Fire dynamics simulator (version 5), user's guide [J]. NIST Special Publication, 2010. 1019(5), 1-186. 